\title{
Do multifocal or multicentric pT1a node-negative HER2+ breast cancers get benefit from systemic treatment?
}

\author{
Kadri Altundag ${ }^{1}$ (D)
}

Received: 8 November 2019 / Accepted: 8 December 2019 / Published online: 14 December 2019

(c) Springer Science+Business Media, LLC, part of Springer Nature 2019

\section{Dear Editor,}

I want to congratulate Kubo et al. [1] for their article in which they studied the effects of adjuvant chemotherapy and/or trastuzumab and survival outcomes among 2736 patients with small $(\leq 2 \mathrm{~cm})$, node-negative, human epidermal growth factor receptor 2 (HER2)-positive breast cancer, using data from the population-based Japanese National Clinical Database (NCD). NCD data revealed that systemic treatment improved OS in pT1b, and pT1c, but not in pT1a node-negative HER2+ breast cancer patients. Multifocal (MF) and multicentric (MC) breast cancers are relatively common clinical entities ranging from 6 to $60 \%$. TNM-staging guidelines have been used to stage MF and MC patients according to the diameter of the largest lesions, without taking other foci of disease into consideration [2]. Furthermore, we evaluated the prognostic performance of determining the $\mathrm{T}$ stage according to the total size of lesions compared with the size of the largest lesion in the breast in patients with MF/MC breast cancer. The T stage of MF/MC tumors was determined according to the largest lesion size (Tmax) as well as the sum of the longest diameters of the lesions (Tsum) in the breast. MF/MC tumors were identified in 323 of 3890 patients ( $8.3 \%$ ) with breast cancer. After the $\mathrm{T}$ stage was reassessed using Tsum, it was observed that the DFS of the 32 patients with MF/MC tumors whose T stage advanced from stage I to II was closer to patients with stage II tumors ,compared with those with stage I [3]. Considering
pT1a MF or MC cases, one would expect that these cases would be staged up to pT1b or pT1c if multiple foci sum up. This issue should be clarified by authors to define robust benefit of treatment in pTla cases.

Funding No funding.

\section{Compliance with ethical standards}

Conflict of interest I declare that I have no conflict of interest.

Ethical approval This article does not contain any studies with human participants or animals performed by any of the authors.

\section{References}

1. Kubo M, Kawai M, Kumamaru H et al (2019) A population-based recurrence risk management study of patients with pT1 node-negative HER2+ breast cancer: a National Clinical Database study. Breast Cancer Res Treat 178(3):647-656

2. Edge SB, Byrd DR, Compton CC et al (2009) AJCC cancer staging manual, 7th edn. Springer, New York

3. Karakas Y, Dizdar O, Aksoy S (2018) The effect of total size of lesions in multifocal/multicentric breast cancer on survival. Clin Breast Cancer 18(4):320-327

Publisher's Note Springer Nature remains neutral with regard to jurisdictional claims in published maps and institutional affiliations.
Kadri Altundag

altundag66@yahoo.com

1 MKA Breast Cancer Clinic, Tepe Prime, Cankaya, 06800 Ankara, Turkey 